\title{
Muscle Quality is More Impaired in Sarcopenic Patients With Chronic Obstructive Pulmonary Disease
}

Citation for published version (APA):

van de Bool, C., Gosker, H. R., van den Borst, B., op den Kamp, C., Slot, I., \& Schols, A. M. W. J. (2016). Muscle Quality is More Impaired in Sarcopenic Patients With Chronic Obstructive Pulmonary Disease. Journal of the American Medical Directors Association, 17(5), 415-420.

https://doi.org/10.1016/j.jamda.2015.12.094

Document status and date:

Published: 01/05/2016

DOI:

10.1016/j.jamda.2015.12.094

Document Version:

Publisher's PDF, also known as Version of record

Document license:

Taverne

Please check the document version of this publication:

- A submitted manuscript is the version of the article upon submission and before peer-review. There can be important differences between the submitted version and the official published version of record.

People interested in the research are advised to contact the author for the final version of the publication, or visit the DOI to the publisher's website.

- The final author version and the galley proof are versions of the publication after peer review.

- The final published version features the final layout of the paper including the volume, issue and page numbers.

Link to publication

\footnotetext{
General rights rights.

- You may freely distribute the URL identifying the publication in the public portal. please follow below link for the End User Agreement:

www.umlib.nl/taverne-license

Take down policy

If you believe that this document breaches copyright please contact us at:

repository@maastrichtuniversity.nl

providing details and we will investigate your claim.
}

Copyright and moral rights for the publications made accessible in the public portal are retained by the authors and/or other copyright owners and it is a condition of accessing publications that users recognise and abide by the legal requirements associated with these

- Users may download and print one copy of any publication from the public portal for the purpose of private study or research.

- You may not further distribute the material or use it for any profit-making activity or commercial gain

If the publication is distributed under the terms of Article $25 \mathrm{fa}$ of the Dutch Copyright Act, indicated by the "Taverne" license above, 
Original Study

\title{
Muscle Quality is More Impaired in Sarcopenic Patients With Chronic Obstructive Pulmonary Disease
}

\author{
Coby van de Bool MSc, Harry R. Gosker PhD, Bram van den Borst PhD, MD, \\ Celine M. Op den Kamp PhD, MD, Ilse G.M. Slot PhD, Annemie M.W.J. Schols PhD*
}

Department of Respiratory Medicine, NUTRIM School of Nutrition and Translational Research in Metabolism, Maastricht University Medical Center+, Maastricht, The Netherlands

Keywords:

COPD

muscle fiber

sarcopenia

\begin{abstract}
A B S T R A C T
Background: Quadriceps muscle fiber atrophy and a loss of oxidative type I muscle fibers and mitochondrial content often occur in chronic obstructive pulmonary disease (COPD), which adversely affects exercise performance. Sarcopenia is an age-related syndrome characterized by wasting and weakness of muscle mass. We recently showed in a large cohort of patients that COPD-related sarcopenia, in particular in male patients, was not only associated with impaired quadriceps muscle strength but also with decreased exercise performance endurance, which could imply involvement of altered muscle fiber type composition. Hence, we hypothesized that both the fiber atrophy and loss of oxidative muscle fibers are more pronounced in sarcopenic compared with nonsarcopenic patients with COPD.

Objective: The objective of this study was to investigate quadriceps muscle fiber-type characteristics in relation to presence of sarcopenia in patients with COPD and in healthy age-matched controls.

Design: For this retrospective cross-sectional study, body composition (assessed by dual-energy x-ray absorptiometry) and quadriceps muscle biopsy (fiber type distribution and sizes) data were collected from 45 patients with COPDs (aged 42-77 years) and 52 healthy controls (aged 50-77 years). Sarcopenia was based on assessment of appendicular skeletal muscle mass index.

Results: Sarcopenia was found in $5.8 \%$ of healthy controls and in $31.1 \%$ of patients with $\operatorname{COPD}(P<.01)$. The proportion of oxidative type I fibers and size of type IIx muscle fibers were decreased in patients with COPD, and the sarcopenic subgroup showed a further decreased proportion as well as a lower size of type I fibers.

Conclusions: Type I muscle fiber proportion is lower in sarcopenic compared with nonsarcopenic patients with COPD. Longitudinal studies may elucidate if the loss of muscle oxidative phenotype drives or accelerates the process of muscle wasting.
\end{abstract}

(c) 2016 AMDA - The Society for Post-Acute and Long-Term Care Medicine.
Muscle wasting is a major hallmark of patients with chronic obstructive pulmonary disease (COPD) besides impaired lung function and contributes to impaired exercise capacity, ${ }^{1}$ decreased health sta-

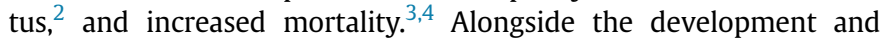
positioning of new radiographic measurements of body composition as integrated part of disease phenotyping, nutritional assessment has

The present study was financially supported by the Lung Foundation Netherlands (grant number: 3.4.09.003). The original 2 studies were financially supported by the Lung Foundation Netherlands (grant number: 96.16) and the Dutch Cancer Institution (grant number UM 2006-3703).

The authors declare no conflicts of interest.

* Address correspondence to Annemie M.W.J. Schols, PhD, Department of Respiratory Medicine, NUTRIM School of Nutrition and Translational Research in Metabolism, Maastricht University Medical Center+, PO Box 616, 6200 MD, Maastricht, The Netherlands.

E-mail address: a.schols@maastrichtuniversity.nl (A.M.W.J. Schols). shifted from a body weight-centered to a body composition-centered approach. Recently, the European Respiratory Society taskforce on Nutritional assessment and therapy in $\mathrm{COPD}^{5}$ proposed dual energy $\mathrm{X}$ ray absorptiometry as the most appropriate method for body composition analysis in COPD, as it allows for screening of osteoporosis combined with assessment of fat mass (FM) and fat-free mass (FFM) at regional levels in addition to whole body level. Assessment of the appendicular skeletal muscle mass index (ASMI) traditionally originates from identification of age-related low muscle mass in elderly populations, a syndrome described as sarcopenia. ${ }^{6}$ Its application is relatively new in COPD, but might in theory be highly relevant as COPD is suggested as disease of accelerated aging. ${ }^{7}$ Indeed, we recently identified sarcopenia in the majority of Dutch patients with COPD eligible for pulmonary rehabilitation across all body mass index (BMI) categories. ${ }^{8}$ Moreover, in this large cohort of patients $(\mathrm{n}=505)$, we demonstrated that low ASMI was not only associated with 
impaired quadriceps muscle strength but, in particular in men, also with decreased cycle exercise endurance and walking distance. Whereas decreased muscle strength directly results from loss of peripheral skeletal muscle mass, ${ }^{9}$ this does not apply for the loss of endurance, which is rather associated with loss of oxidative phenotype. ${ }^{10}$ Consequently, it could be hypothesized that sarcopenia in COPD is characterized by intrinsic muscular alterations as well. In COPD, consistent intrinsic alterations in peripheral skeletal muscles have indeed been described. ${ }^{11}$ More specifically, quadriceps muscle in advanced COPD is characterized by predominant atrophy of type IIx fibers ${ }^{12}$ as well as a loss of oxidative phenotype (ie, a shift from oxidative type I to glycolytic II muscle fibers). ${ }^{13}$ Furthermore, van den Borst et al ${ }^{14}$ previously demonstrated that loss of quadriceps oxidative phenotype and decreased quadriceps endurance was already present in patients with mild-to-moderate COPD in the absence of muscle and fiber atrophy.

These alterations culminate in reduced muscle endurance, but in addition, could also drive or accelerate muscle wasting because the loss of muscle oxidative phenotype may render muscle in COPD less energy efficient, and (the remaining) type II fibers are more sensitive to atrophying disease-related triggers. ${ }^{15-17}$ Moreover, intrinsic abnormalities in peripheral muscle seem more aggravated in emphysematous patients who are also more susceptible to weight loss. ${ }^{18-20}$ In addition, Gouzi et $\mathrm{al}^{21}$ recently identified an atrophic cluster of patients with COPD with reduced BMI, FFMI, type I fiber proportion, and fiber cross-sectional area (CSA) using an unsupervised clustering method.

Although assessment of muscle fiber alterations is crucial for understanding the process of muscle wasting in COPD, data is lacking on differences in muscle fiber-type characteristics between sarcopenic and nonsarcopenic patients with COPD. Therefore, the aim of this retrospective study was to compare quadriceps muscle fiber-type characteristics in relation to sarcopenia ${ }^{6}$ in patients with COPD and in healthy controls. We hypothesize that muscle fiber atrophy and loss of oxidative muscle fibers are more pronounced in the sarcopenic COPD phenotype.

\section{Methods}

\section{Participants}

The studied population consisted of 45 clinically stable patients with COPD and 52 healthy controls. All patients were recruited from the outpatient clinic of the Maastricht University Medical Center+ (Maastricht, The Netherlands) and via local newspapers advertisement. Exclusion criteria comprised use of long-term oxygen therapy or oral prednisolone, acute exacerbation with hospital admission in the previous 4-8 weeks, or rehabilitation in the previous 6 months. Patients with known comorbidities as diabetes, recent cardiovascular event, inflammatory bowel disease, obstructive sleep apnea, thyroid disease, and cancer were carefully excluded because of potential interference with study outcomes. Healthy controls were recruited via local newspaper advertisement. Absence of diseases was verified through history-taking by a physician, and absence of airflow limitation was verified by pulmonary function tests. All patients participated in 1 out of 3 cross-sectional studies of which data has been previously published. ${ }^{12,14,22}$ Participants were included in 1996-1997, July 2007-July 2010, and March 2009April 2010.

\section{Ethics}

The procedures followed were in accordance with the ethical standards of the responsible institutional or regional committee on human experimentation or in accordance with the Helsinki Declaration of 1975 as revised in 1983.

\section{Lung Function Measurement}

In accordance with the latest Global Initiative for Chronic Obstructive Lung Disease (GOLD) guidelines, ${ }^{23}$ standardized equipment (Masterlab, Jaeger, Germany) was used to assess postbronchodilator forced expiratory volume in 1 second $\left(\mathrm{FEV}_{1}\right)$ and forced vital capacity. Diffusion capacity of carbon monoxide was assessed by single-breath method. All obtained values were expressed as percentages of the predicted value, by comparison with age and gender-specific reference values. ${ }^{24}$

\section{Body Composition and Muscle Phenotyping}

Total body height was measured to the nearest $0.5 \mathrm{~cm}$ with a wallmounted stadiometer and total body weight to the nearest $0.1 \mathrm{~kg}$ using a weighing scale. BMI was calculated as weight/height ${ }^{2}\left(\mathrm{~kg} / \mathrm{m}^{2}\right)$. Body composition was measured by dual energy $\mathrm{x}$-ray absorptiometry (Lunar Prodigy System, GE Healthcare, Madison, WI; Hologic Discovery, Hologic, Bedford, MA). Fat-free mass index (FFMI) was calculated by dividing FFM (lean mass + bone mineral content) by height ${ }^{2}$ and fat mass by subtracting FFM from body weight. Sarcopenia was defined according to cut-offs for ASMI $\left(<7.23 \mathrm{~kg} / \mathrm{m}^{2}\right.$ for men; $<5.67 \mathrm{~kg} / \mathrm{m}^{2}$ for women). ${ }^{6}$

\section{Muscle Fiber Typing}

Quadriceps muscle biopsy analyses have previously been described in detail for the 3 individual studies. ${ }^{12,14,22}$ In short, needle biopsies were obtained from the vastus lateralis under local anesthesia. Samples were frozen in melting isopentane (precooled in liquid nitrogen) and serial $5 \mu \mathrm{m}$ cryosections were cut. A combination of myosin ATPase-activity staining and immunohistochemistry (antibodies against different myosin heavy chain isoforms) was applied to determine fiber type proportions and fiber cross-sectional areas using imaging software. All samples were analyzed within a year after collection.

\section{Statistical Analyses}

The Statistical Package for Social Sciences version 20.0 (SPSS, Inc, Chicago, IL) was used to perform statistical analyses. Normal distribution was assed using the Shapiro-Wilk test. Discrete variables were compared by the $\chi^{2}$ test and presented as percentages. Continuous variables were presented as median \pm interquartile range (characteristics) or mean \pm standard error (muscle fiber composition) and were compared between 2 groups by the Student $t$-test for independent samples (parametric data) or Mann-Whitney test (nonparametric data), and compared between more than 2 groups by 1-way analysis of variance (parametric data) or Kruskal-Wallis test (nonparametric data). Two-sided $P$ values of $<.05$ were considered statistically significant.

Because of a too small number of female participants, we could not perform separate analyses for males and females. Nonetheless, separate analyses could be performed for males, which are presented in the online supplement.

\section{Results}

Participant Characteristics

Both the COPD and healthy control groups consisted mostly of men (64.6\% and $67.9 \% ; P=.723$ ). The majority of patients with COPD had 
Table 1

Participant Characteristics

\begin{tabular}{|c|c|c|c|}
\hline & Nonsarcopenic Control $(n=49)$ & Nonsarcopenic COPD $(\mathrm{n}=31)$ & Sarcopenic COPD $(\mathrm{n}=14)$ \\
\hline \multicolumn{4}{|c|}{ General characteristics } \\
\hline Male, \% & 65.3 & 51.6 & $92.9^{*}$ \\
\hline Age, years & $64.0(59.5-67.0)$ & $65.0(61.0-69.0)$ & $68.0(66.8-74.3)^{\dagger}$ \\
\hline $\mathrm{FEV}_{1}, \%$ predicted & $112.8(103.9-123.8)$ & $57.3(45.8-69.5)^{\dagger}$ & $42.1(33.0-49.3)^{*, \dagger}$ \\
\hline FVC, \%predicted & $121.8(113.8-135.4)$ & $103.0(83.5-116.3)^{\dagger}$ & $86.4(76.1-117.5)^{\dagger}$ \\
\hline $\mathrm{FEV}_{1} / \mathrm{FVC}, \%$ & $92.5(86.6-98.7)$ & $59.3(48.2-67.7)^{\dagger}$ & $42.3(36.5-46.8)^{*, \dagger}$ \\
\hline DICO, \%predicted & $104.2(90.2-120.3)$ & $55.4(40.0-67.8)^{\dagger}$ & $42.2(35.6-70.1)^{\dagger}$ \\
\hline GOLD I/II/III/IV, \% & & $10 / 50 / 36.7 / 3.3$ & $0 / 14.3 / 71.4 / 14.3^{*}$ \\
\hline \multicolumn{4}{|l|}{ Body composition } \\
\hline Height, cm & $173.0(166.3-178.8)$ & $168.0(158.0-175.0)^{\dagger}$ & $171.9(165.2-176.6)$ \\
\hline BMI, $\mathrm{kg} / \mathrm{m}^{2}$ & $25.5(23.3-28.2)$ & $25.8(23.6-27.8)$ & $23.5(20.6-25.7)^{*, \dagger}$ \\
\hline FFMI, $\mathrm{kg} / \mathrm{m}^{2}$ & $19.0(17.2-20.3)$ & $18.2(15.8-19.4)$ & $16.8(16.2-17.5)^{*, \dagger}$ \\
\hline ASMI, $\mathrm{kg} / \mathrm{m}^{2}$ & $8.2(6.9-8.7)$ & $7.3(6.3-7.9)^{\dagger}$ & $7.0(6.5-7.1)^{\dagger}$ \\
\hline FMI, $\mathrm{kg} / \mathrm{m}^{2}$ & $6.0(4.8-8.3)$ & $7.2(5.8-10.0)$ & $6.3(3.5-7.7)^{*}$ \\
\hline Fat percentage, \% & $25.1(19.1-30.6)$ & $28.7(24.1-37.0)^{\dagger}$ & $26.4(19.5-31.2)$ \\
\hline
\end{tabular}

DICO, diffusion capacity of carbon monoxide; FVC, forced vital capacity; IQR, interquartile range.

Results presented as median (IQR).

*Statistically different from nonsarcopenic patients with COPD.

${ }^{\dagger}$ Statistically different from nonsarcopenic controls.

moderate to severe impaired lung function, as $6.4 \%$ of patients were classified in GOLD stage I, 36.2\% in GOLD stage II, $48.9 \%$ in GOLD stage III, and $8.5 \%$ in GOLD stage IV.

Applying the gender-specific cut-offs for ASMI revealed presence of sarcopenia in 3 male healthy controls, 1 female patient with COPD, and 13 male patients with COPD, resulting in a total of $5.8 \%$ of healthy controls, compared with $31.1 \%$ in patients with COPD $(P<.01)$. In males, $8.6 \%$ of control participants were sarcopenic, compared with $44.8 \%$ in patients with COPD $(P<.01)$. Healthy controls with sarcopenia were excluded in further analyses because of the low number of participants.

Table 1 shows the participant characteristics per metabolic phenotype. Sarcopenic patients with COPDs were of similar age as nonsarcopenic patients, but were slightly older compared with the nonsarcopenic healthy controls (68 vs 64 years of age; $P<.001$ ). In addition, airflow limitation was more pronounced in sarcopenia compared with nonsarcopenic patients with COPD (FEV $142.1 \%$ predicted vs $\mathrm{FEV}_{1} 57.3 \%$ predicted). However, age and $\mathrm{FEV}_{1}$ were no significant predictors for ASMI in a regression model, whereas participant group (control or COPD) significantly predicted ASMI $(P<.01)$. Nonsarcopenic patients with COPD had a higher fat percentage compared with nonsarcopenic controls. In line with a lower ASMI, sarcopenic patients with COPD showed a lower BMI, FFMI, and FMI than nonsarcopenic patients with COPD. Similar results were found in males only (Supplemental Table 1).

\section{Quadriceps Muscle Fiber Type Composition}

Figure 1 shows the proportion of type I muscle fibers across groups. In comparison with nonsarcopenic controls, a significantly lower proportion of type I fibers was found in both sarcopenic $(26.0 \%$ vs $50.7 \%, P<.001$ ) and nonsarcopenic patients with COPD (38.7 vs $50.7 \%, P<.01)$. Furthermore, the proportion of type I fibers was significantly lower in sarcopenic patients with COPD than nonsarcopenic patients $(P=.048)$. Analyses in males showed similar results (Supplemental Figure 1).

The comparison of muscle fiber types CSA across groups is shown in Figure 2. In general, patients with COPD showed a significantly lower CSA of type IIx muscle fiber compared with nonsarcopenic controls (3464 vs $4472 \mu \mathrm{m}^{2} ; P<.05$ ), but no differences were found across sarcopenic phenotypes in COPD. In addition, CSA of type I fibers were significantly lower in sarcopenic patients with COPD compared with nonsarcopenic patients (5726 vs $\left.7879 \mu \mathrm{m}^{2} ; P<.05\right)$. No significant differences were found in CSA of type I/IIa, Ila, IIa/IIx muscle fiber, or mean CSA, although CSA of type IIa/IIx and mean CSA tended to be lower in sarcopenic patients. Comparisons in males showed an additional difference in CSA of type IIa/IIx fibers, which were significantly lower in sarcopenic patients than nonsarcopenic patients (4280 vs $\left.6411 \mu \mathrm{m}^{2} ; P<.05\right)$ (Supplemental Figure 2).

\section{Discussion}

This is the first study investigating quadriceps muscle fiber-type characteristics in relation to sarcopenia in patients with COPD and in healthy controls. Previous studies have already demonstrated a loss of muscle oxidative phenotype, including a muscle fiber type $\mathrm{I} \rightarrow \mathrm{II}$ shift, ${ }^{13,14}$ and selective atrophy of the type Ilx fibers ${ }^{12}$ in patients with COPD. Added to the existing knowledge, the novelty of the current study is that it demonstrates a more pronounced decrease in oxidative type I fiber proportion in patients with COPD and sarcopenia.

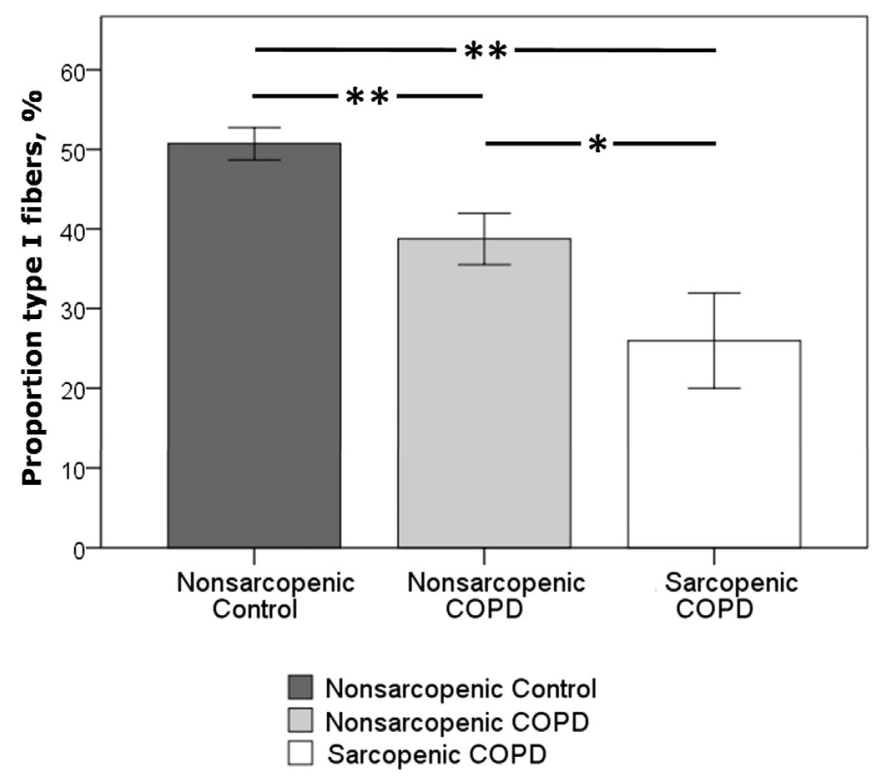

Fig. 1. Comparison of muscle fiber composition across groups. *Significant at $P<.05$; **Significant at $P<.01$. 

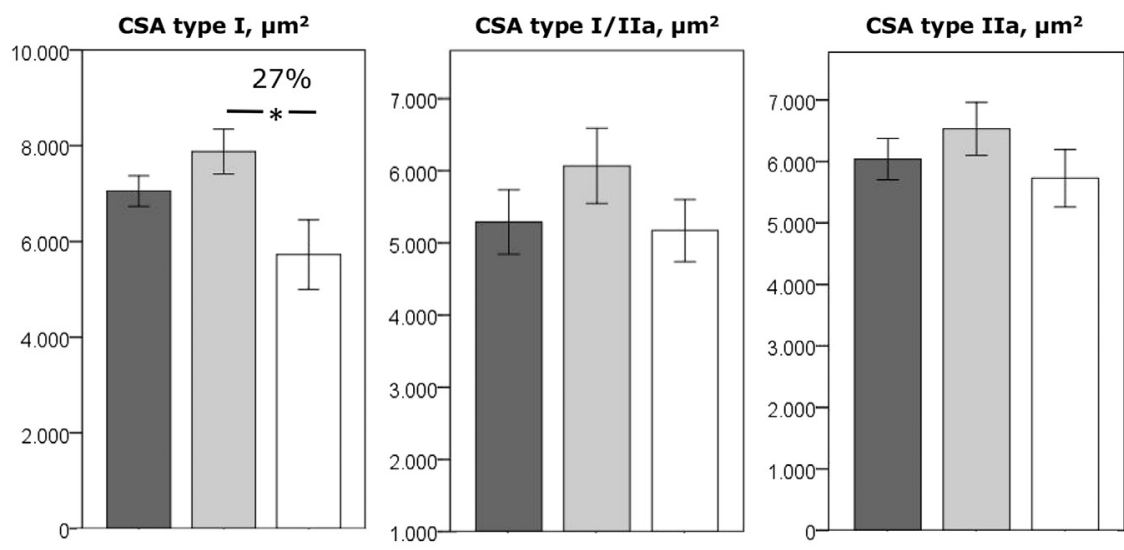

Nonsarcopenic Control Nonsarcopenic COPD Sarcopenic COPD
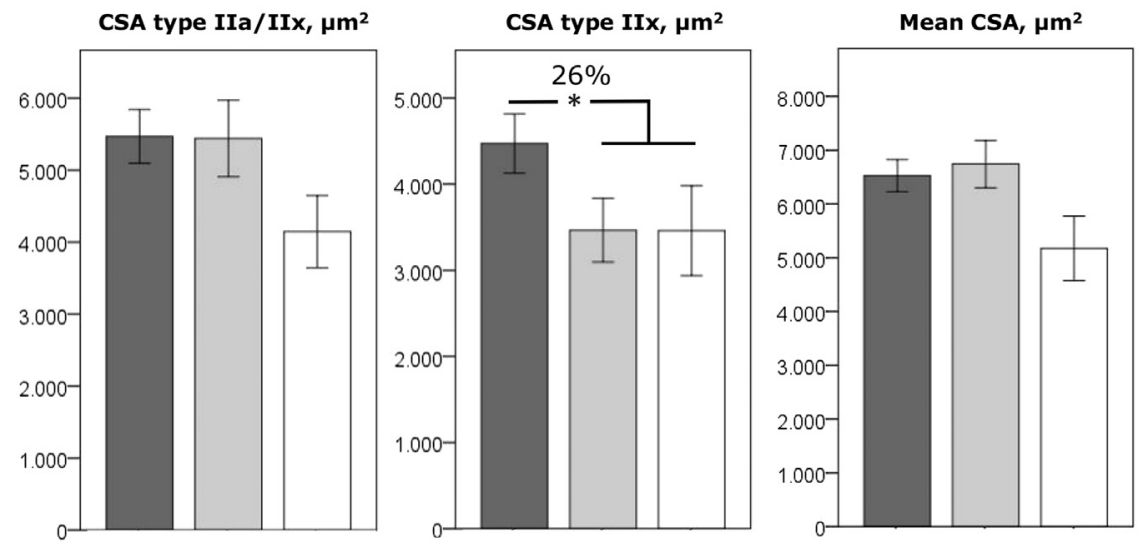

Fig. 2. Comparison of muscle fiber CSA across groups. *Significant at $P<.05$.

Moreover, these sarcopenic patients are characterized by selective atrophy of the type I fibers, which seems independent of the more generalized type II atrophy in COPD as a whole.

Applying the ASMI cut-offs in our study population revealed sarcopenia in $31.1 \%$ of the patients with COPD and $5.8 \%$ of the healthy control participants. A comparable proportion of sarcopenic patients with COPD was found in a South Korean noninstitutionalized civilian population, in which $32.8 \%$ of male and $12.2 \%$ of female patients with COPDs were sarcopenic, ${ }^{25}$ as well as in a Brazilian COPD outpatient clinic, in which sarcopenia was observed in $39.6 \%$ of the patients. ${ }^{26}$ We recently reported a considerably higher proportion of sarcopenia in more patients with advanced COPD eligible for a pulmonary rehabilitation program. ${ }^{8}$ This is not surprising as skeletal muscle weakness is an important determinant of impaired exercise performance as important indication for referral to pulmonary rehabilitation.

Regarding muscle fiber composition, we found a significant decrease in CSA of type IIx fibers in the patient group compared with the (nonsarcopenic) healthy control group, which is in line with previous reports. $^{12,27,28}$ The type IIx muscle fiber atrophy was not related to sarcopenia, as it was present in both sarcopenic and nonsarcopenic patients. Nonetheless, CSA of type IIa/IIx fibers tended to be lower in sarcopenic patients than in nonsarcopenic patients reaching statistical significance in the male subgroup (Supplemental Figure 2). Multiple disease-related triggers, occurring in isolation or combined, have been suggested to contribute to the atrophy of type II muscle fibers in COPD. Putative catabolic triggers include nutritional depletion, inflammation, oxidative stress, and myostatin. ${ }^{29,30}$ Nutritional depletion often occurs in COPD and is a likely contributor to atrophy of type II fibers based on collective findings of studies on anorexia nervosa, chronic heart failure, AIDS, and chronic renal failure. ${ }^{12}$ In addition, the majority of patients with COPD, especially muscle-wasted patients, ${ }^{31}$ exhibit chronic low-grade inflammation with elevated circulating concentrations of tumor necrosis factor- $\alpha$, mediating muscle atrophy via the inflammatory signaling pathway nuclear factor $\kappa \mathrm{B} .{ }^{32}$ Furthermore, muscle-wasted patients with COPD show elevated concentrations of myostatin ${ }^{33}$ and systemic oxidative stress, ${ }^{34}$ which have also been shown to correlate negatively with muscle mass in patients with COPD. $^{33,34}$

In addition to muscle atrophy, peripheral muscle in COPD is characterized by a I-to-II fiber type shift, leading to an impaired oxidative phenotype. ${ }^{13}$ Long-term disuse has been described as catabolic trigger preferentially affecting type I muscle fibers. ${ }^{35}$ Indeed, our patients with COPD displayed a decreased proportion of type I fibers in comparison with healthy controls. Moreover, this shift was even more pronounced in sarcopenic patients with COPD, accompanied by a clear reduction in the CSA in the type I muscle fibers. In the literature, prolonged inactivity has indeed been described as an important driver for sarcopenia, as the sarcopenic process seems attenuated by higher levels of physical activity ${ }^{36}$ and effects of inactivity result in accelerated loss of skeletal muscle and functional capacity. ${ }^{37}$

Collectively, the present findings confirm our hypothesis of a more pronounced loss of oxidative phenotype in sarcopenic patients with COPD and correspond with our previous finding of decreased muscle strength and endurance in sarcopenic patients with COPD. In addition to reduced exercise capacity, ${ }^{38}$ loss of oxidative phenotype might potentially accelerate muscle wasting. First, a shift toward more type II fibers will lead to an increased reliance on glycolytic metabolism, contributing to metabolic inefficiency. Furthermore, type II fibers are more susceptible to atrophying disease-related triggers as inflammation-induced and oxidative stress-induced damage. ${ }^{15-17}$ 
Moreover, fiber shifting in the vastus lateralis of patients with COPD was recently identified as an independent predictor of mortality in patients with severe to very severe COPD. ${ }^{39}$

Some limitations of the present study deserve discussion. Nowadays, the European Working Group on Sarcopenia in Older People recommends using the presence of low physical function (strength or performance) next to low ASMI. ${ }^{40}$ The current study design was retrospective, restraining the availability of a functional measure performed in each of the 3 study populations. Therefore, sarcopenia was diagnosed based on the presence of low ASMI only. None of the subgroups was confined to a single study population and because only standardized and routine measurements were studied, we are confident that this did not introduce selection bias. Furthermore, the study design was cross-sectional, and although this was suitable to answer the current research question, longitudinal studies monitoring how fiber type alterations develop as the muscle wasting process progresses are required to disentangle the cause and consequence. Finally the unequal gender distribution between the subgroups does not rule out putative gender differences in the association between sarcopenia and loss of oxidative phenotype.

The current study supports exercise training programs for patients with COPD that combine resistance and aerobic exercises as commonly applied in pulmonary rehabilitation, or combining endurance exercise with anabolics. Myostatin inhibitors, for example, are currently investigated as promising anabolic pharmacologic agents for restoring muscle mass. However, some studies suggest that inhibition of myostatin might have detrimental effects on the oxidative capacity of muscle fibers, ${ }^{41-44}$ which could be combatted by a multimodal intervention approach.

In conclusion, this study shows evidence for a more pronouncedly decreased type I fiber proportion in sarcopenic patients with COPD. These findings could reflect a cross-talk between muscle mass and oxidative phenotype regulation, which might accelerate the muscle wasting process in patients with COPD.

\section{Supplementary Data}

Supplementary data related to this article can be found at http:// dx.doi.org/10.1016/j.jamda.2015.12.094.

\section{References}

1. Engelen MP, Schols AM, Baken WC, et al. Nutritional depletion in relation to respiratory and peripheral skeletal muscle function in out-patients with COPD. Eur Respir J 1994;7:1793-1797.

2. Mostert R, Goris A, Weling-Scheepers C, et al. Tissue depletion and health related quality of life in patients with chronic obstructive pulmonary disease. Respir Med 2000;94:859-867.

3. Schols AM, Broekhuizen R, Weling-Scheepers CA, Wouters EF. Body composition and mortality in chronic obstructive pulmonary disease. Am J Clin Nutr 2005;82:53-59.

4. Marquis K, Debigare R, Lacasse Y, et al. Midthigh muscle cross-sectional area is a better predictor of mortality than body mass index in patients with chronic obstructive pulmonary disease. Am J Respir Crit Care Med 2002;166:809-813.

5. Schols AM, Ferreira IM, Franssen FM, et al. Nutritional assessment and therapy in COPD: A European Respiratory Society statement. Eur Respir J 2014;44: 1504-1520.

6. Newman AB, Kupelian V, Visser M, et al. Sarcopenia: Alternative definitions and associations with lower extremity function. J Am Geriatr Soc 2003;51: 1602-1609.

7. Mui TS, Man JM, McElhaney JE, et al. Telomere length and chronic obstructive pulmonary disease: Evidence of accelerated aging. J Am Geriatr Soc 2009;57: $2372-2374$.

8. van de Bool C, Rutten EP, Franssen FM, et al. Antagonistic implications of sarcopenia and abdominal obesity on physical performance in COPD. Eur Respir J 2015;46:336-345.

9. Bernard S, LeBlanc P, Whittom F, et al. Peripheral muscle weakness in patients with chronic obstructive pulmonary disease. Am J Respir Crit Care Med 1998; 158:629-634.
10. Allaire J, Maltais F, Doyon JF, et al. Peripheral muscle endurance and the oxidative profile of the quadriceps in patients with COPD. Thorax 2004;59: 673-678.

11. Mathur S, Brooks D, Carvalho CR. Structural alterations of skeletal muscle in copd. Front Physiol 2014;5:104.

12. Gosker HR, Engelen MP, van Mameren H, et al. Muscle fiber type IIX atrophy is involved in the loss of fat-free mass in chronic obstructive pulmonary disease. Am J Clin Nutr 2002;76:113-119.

13. Gosker HR, Zeegers MP, Wouters EF, Schols AM, et al. Muscle fibre type shifting in the vastus lateralis of patients with COPD is associated with disease severity: A systematic review and meta-analysis. Thorax 2007;62: 944-949.

14. van den Borst B, Slot IG, Hellwig VA, et al. Loss of quadriceps muscle oxidative phenotype and decreased endurance in patients with mild-to-moderate COPD. J Appl Physiol (1985) 2013;114:1319-1328.

15. Wang Y, Pessin JE. Mechanisms for fiber-type specificity of skeletal muscle atrophy. Curr Opin Clin Nutr Metab Care 2013:16:243-250.

16. Schakman O, Kalista S, Barbe C, et al. Glucocorticoid-induced skeletal muscle atrophy. Int J Biochem Cell Biol 2013;45:2163-2172.

17. de Theije CC, Langen RC, Lamers WH, et al. Differential sensitivity of oxidative and glycolytic muscles to hypoxia-induced muscle atrophy. J Appl Physiol (1985) 2015;118:200-211.

18. Gosker HR, van Mameren H, van Dijk PJ, et al. Skeletal muscle fibre-type shifting and metabolic profile in patients with chronic obstructive pulmonary disease. Eur Respir J 2002;19:617-625.

19. Rabinovich RA, Bastos R, Ardite E, et al. Mitochondrial dysfunction in COPD patients with low body mass index. Eur Respir J 2007:29:643-650.

20. Remels AH, Gosker HR, Schrauwen P, et al. TNF-alpha impairs regulation of muscle oxidative phenotype: Implications for cachexia? FASEB J 2010;24: 5052-5062.

21. Gouzi F, Abdellaoui A, Molinari N, et al. Fiber atrophy, oxidative stress, and oxidative fiber reduction are the attributes of different phenotypes in chronic obstructive pulmonary disease patients. J Appl Physiol (1985) 2013;115: 1796-1805.

22. Op den Kamp CM, Langen RC, Snepvangers FJ, et al. Nuclear transcription factor kappa B activation and protein turnover adaptations in skeletal muscle of patients with progressive stages of lung cancer cachexia. Am J Clin Nutr 2013; 98:738-748.

23. Vestbo J, Hurd SS, Agusti AG, et al. Global strategy for the diagnosis, management, and prevention of chronic obstructive pulmonary disease: GOLD executive summary. Am J Respir Crit Care Med 2013;187:347-365.

24. Clausen JL, Coates AL, Quanjer PH. Measurement of lung volumes in humans: Review and recommendations from an ATS/ERS workshop. Eur Respir J 1997; 10:1205-1206.

25. Chung JH, Hwang HJ, Han CH, et al. Association between sarcopenia and metabolic syndrome in chronic obstructive pulmonary disease: The Korea National Health and Nutrition Examination Survey (KNHANES) from 2008 to 2011. COPD 2015;12:82-89.

26. Costa TM, Costa FM, Moreira CA, et al. Sarcopenia in COPD: Relationship with COPD severity and prognosis. J Bras Pneumol 2015;41:415-421.

27. Fermoselle C, Rabinovich R, Ausin P, et al. Does oxidative stress modulate limb muscle atrophy in severe COPD patients? Eur Respir J 2012;40: $851-862$

28. Natanek SA, Riddoch-Contreras J, Marsh GS, et al. Yin Yang 1 expression and localisation in quadriceps muscle in COPD. Arch Bronconeumol 2011;47: 296-302.

29. Remels AH, Gosker HR, Langen RC, Schols AM. The mechanisms of cachexia underlying muscle dysfunction in COPD. J Appl Physiol (1985) 2013;114: $1253-1262$.

30. Langen RC, Gosker HR, Remels AH, Schols AM. Triggers and mechanisms of skeletal muscle wasting in chronic obstructive pulmonary disease. Int J Biochem Cell Biol 2013;45:2245-2256.

31. Van Helvoort HA, Heijdra YF, Thijs HM, et al. Exercise-induced systemic effects in muscle-wasted patients with COPD. Med Sci Sports Exerc 2006;38: 1543-1552.

32. Li H, Malhotra S, Kumar A. Nuclear factor-kappa B signaling in skeletal muscle atrophy. J Mol Med (Berl) 2008;86:1113-1126.

33. Ju CR, Chen RC. Serum myostatin levels and skeletal muscle wasting in chronic obstructive pulmonary disease. Respir Med 2012;106:102-108.

34. van Helvoort HA, Heijdra YF, de Boer RC, et al. Six-minute walking-induced systemic inflammation and oxidative stress in muscle-wasted COPD patients. Chest 2007;131:439-445.

35. Murton AJ, Greenhaff PL. Physiological control of muscle mass in humans during resistance exercise, disuse and rehabilitation. Curr Opin Clin Nutr Metab Care 2010;13:249-254.

36. Hughes VA, Roubenoff R, Wood M, et al. Anthropometric assessment of 10year changes in body composition in the elderly. Am J Clin Nutr 2004;80: 475-482.

37. Evans WJ. Skeletal muscle loss: Cachexia, sarcopenia, and inactivity. Am J Clin Nutr 2010:91:1123S-1127S.

38. Maltais F, LeBlanc $P$, Whittom F, et al. Oxidative enzyme activities of the vastus lateralis muscle and the functional status in patients with COPD. Thorax 2000; 55:848-853. 
39. Patel MS, Natanek SA, Stratakos G, et al. Vastus lateralis fiber shift is an independent predictor of mortality in chronic obstructive pulmonary disease. Am J Respir Crit Care Med 2014;190:350-352.

40. Cruz-Jentoft AJ, Baeyens JP, Bauer JM, et al. Sarcopenia: European consensus on definition and diagnosis. Age Ageing 2010;39:412-423.

41. Ploquin C, Chabi B, Fouret G, et al. Lack of myostatin alters intermyofibrillar mitochondria activity, unbalances redox status, and impairs tolerance to chronic repetitive contractions in muscle. Am J Physiol Endocrinol Metab 2012: 302:E1000-E1008.
42. Hennebry A, Berry C, Siriett V, et al. Myostatin regulates fiber-type composition of skeletal muscle by regulating MEF2 and MyoD gene expression. Am J Physiol Cell Physiol 2009;296:C525-C534.

43. Girgenrath S, Song K, Whittemore LA. Loss of myostatin expression alters fibertype distribution and expression of myosin heavy chain isoforms in slow- and fast-type skeletal muscle. Muscle Nerve 2005;31:34-40.

44. Baan JA, Kocsis T, Keller-Pinter A, et al. The compact mutation of myostatin causes a glycolytic shift in the phenotype of fast skeletal muscles. J Histochem Cytochem 2013;61:889-900. 